\title{
The use of filter paper plasticized with polyvinyl alcohol-glutaraldehyde in ELISA
}

G.H.T.S. Barbosa ${ }^{1}$, E.M. Santana ${ }^{1,2}$, A.M.P. Almeida ${ }^{4}$ A.M. Araujo $0^{5}$,

0 . Fatibello-Filho ${ }^{6}$ and L.B. Carvalho Jr.1,3

\author{
${ }^{1}$ Laboratório de Imunopatologia Keizo Asami, Departamentos de ${ }^{2}$ M edicina Tropical \\ and ${ }^{3}$ Bioquímica, Universidade Federal de Pernambuco, \\ ${ }^{4}$ Centro de Pesquisas Aggeu Magalhães, FIOCRUZ, and \\ ${ }^{5}$ Fundação de Hematologia e Hemoterapia de Pernambuco, Recife, PE, Brasil \\ ${ }^{6}$ Departamento de Química, U niversidade Federal de São Carlos, São Carlos, \\ $\mathrm{SP}$, Brasil
}

\section{Correspondence}

L.B. Carvalho Jr.

Laboratório de Imunopatologia

Keizo Asami, UFPE

50670-420 Recife, PE

Brasil

Fax: +55-81-271-8485

E-mail: Ibcj@ npd.ufpe.br

Publication supported by FAPESP

Received June 21, 1999

Accepted March 10, 2000

\section{Abstract}

F1-antigen purified from Yersinia pestis was covalently linked to 5$\mathrm{mm}$ diameter filter paper discs plasticized with polyvinyl alcoholglutaraldehyde. These discs were used both for ELISA and dot-ELISA for the detection of anti-F1 IgG in rabbits. The best conditions were achieved using $1.25 \mu \mathrm{g}$ of F1 antigen/disc, 3\% w/v skim milk in PBS as blocking agent, anti-IgG peroxidase conjugate diluted 12,000 times, and serum from rabbits immunized or not against $Y$. pestis, diluted 6,400 times. The absorbance values obtained from the comparative study between this procedure and conventional ELISA were not significantly different but the low cost of the reagents employed in ELISA using the filter paper discs plasticized with polyvinyl alcoholglutaraldehyde makes this method economically attractive.

\section{Introduction}

Plague, an acute tropical disease caused by Yersinia pestis, is still an important public health issue in developing countries (1). Human cases of plague, which had virtually disappeared in Madagascar after the 1930's, reappeared in 1990 with more than 200 confirmed or presumptive cases reported each year since then (2). From 1980 to 1993, 763 cases of plague were recorded in Brazil (3). This disease is unlikely to disappear due to the wide range of mammalian hosts and their attendant fleas (4). On the other hand, the presence of significant levels of specific anti-F1A antibodies among rodents and wild or domestic carnivores (dogs and cats) indicates that all Brazilian plague foci remain active in spite of the absence of human cases (5).

The Centro de Pesquisas Aggeu Magalhães/FIOCRUZ is responsible for monitoring the occurrence of new plague cases in Northeastern Brazil. The serologic diagnosis is made by the passive hemagglutination assay (PHA), as recommended by the World Health Organization Committee specialized in plague.

Almeida and Ferreira (6) evaluated the results obtained from PHA, ELISA and dotELISA for the detection of plague-infected patients from Northeastern Brazil and demonstrated that PHA is not a sensitive test due to the large number of false-negative results. Thus, the serologic diagnosis of plague is still an important subject for scientific investigation. 
Detection of anti-F1 IgG by ELISA has also been used for sero-epidemiological studies in Madagascar (7). Modern approaches have been reported such as the use of a fiber optic biosensor $(8,9)$ and a PCR-based procedure (10). In our laboratories, different methods for the serologic diagnosis of this pathology have been proposed (10-14). Dacron plates and polyvinyl alcohol-glutaraldehyde discs have been used in these procedures.

In the present study, filter paper plasticized with polyvinyl alcohol-glutaraldehyde was investigated as support for the serologic diagnosis of plague.

\section{Material and Methods}

\section{Synthesis of filter paper plasticized with polyvinyl alcohol-glutaraldehyde}

Polyvinyl alcohol (0.5 g; Reagen, Rio de Janeiro, RJ, Brazil) was dissolved in $5 \mathrm{ml}$ of deionized water by heating. After cooling at $25^{\circ} \mathrm{C}$, glutaraldehyde $(1.25 \mathrm{ml}$ of $25 \% \mathrm{w} / \mathrm{v}$ solution; Sigma Chemical Co., St. Louis, MO, USA) and $\mathrm{H}_{2} \mathrm{SO}_{4}$ ( $1 \mathrm{ml}$ of a $0.3 \mathrm{M}$ solution) were successively added under stirring. This mixture (about $7.3 \mathrm{ml}$ ) was then poured onto a Petri dish $(9 \mathrm{~cm}$ in diameter) and 1 sheet of filter paper (ADVANTEC Toyo Roshi International, Inc., Dublin, CA, USA), measuring $5.5 \mathrm{~cm}$ in diameter, grade 2, was immersed in the mixture on the Petri dish. The soaked filter paper was allowed to dry at $25^{\circ} \mathrm{C}$ lying on the top of a beaker for 2-3 $\mathrm{h}$. The entire procedure was carried out under a hood.

\section{Antigen and sera}

F1 antigen $(4 \mathrm{mg} / \mathrm{ml})$ from $Y$. pestis was obtained by the method of Baker et al. (15). Sera from rabbits immunized or not against $Y$. pestis and $67 \mu \mathrm{M}$ phosphate-buffered saline (PBS), $\mathrm{pH} \mathrm{7.2,} \mathrm{containing} 1 \mathrm{M} \mathrm{NaCl}$ were used as control. Goat anti-rabbit IgG labeled with horseradish peroxidase was purchased from Sigma.

\section{Antigen immobilization}

The plasticized filter paper was cut into small discs using a paper punch $(5 \mathrm{~mm}$ in diameter). The discs were then introduced into microwells of tissue culture plates containing $100 \mu \mathrm{l}$ of $\mathrm{F} 1$ antigen, diluted to 1:320 $(1.25 \mu \mathrm{g})$ and incubated at $25^{\circ} \mathrm{C}$ for $1 \mathrm{~h}$. These antigen/plasticized discs were then washed twice with PBS containing $0.05 \%$ w/v Tween 20 (Sigma), blocked with skim milk ( $3 \% \mathrm{w} / \mathrm{v}$ in PBS; Molico milk, Nestlé) at $4^{\circ} \mathrm{C}$ for $12 \mathrm{~h}$ and washed once with PBS/Tween.

\section{ELISA}

The antigen/plasticized discs were incubated with $100 \mu \mathrm{l}$ of serum diluted 1:6,400 in $\mathrm{PBS}$ at $37^{\circ} \mathrm{C}$ for $30 \mathrm{~min}$. After washing five times with PBS/Tween, the antigen-antibodydisc complex was incubated with $100 \mu$ of goat anti-rabbit IgG conjugated with horseradish peroxidase, diluted 12,000 times in $\mathrm{PBS}$, at $37^{\circ} \mathrm{C}$ for $30 \mathrm{~min}$. Five washings with PBS/Tween were then carried out. The substrate solution $(100 \mu \mathrm{l})$, consisting of $0.325 \%$ (w/v) orthophenylenediamine dihydrochloride (OPD; Sigma) and $0.085 \%$ v/ $\mathrm{v}_{2} \mathrm{O}_{2}$, prepared in $0.3 \mathrm{M}$ Tris-citrate buffer, $\mathrm{pH} 6.0$, was added and incubated at room temperature $\left(28^{\circ} \mathrm{C}\right)$ for $15 \mathrm{~min}$ in the dark. The reaction was stopped with $2.5 \mathrm{M} \mathrm{H}_{2} \mathrm{SO}_{4}(25$ $\mu \mathrm{l})$, the discs were removed and the plates read in an ELISA reader (Bio-rad) at 492 $\mathrm{nm}$.

\section{Optimization procedure}

The procedure was standardized according to previous studies on the best antigen concentration, blocking conditions, conjugate titration, and sera.

Antigen concentration. Samples $(100 \mu \mathrm{l})$ of $\mathrm{F} 1$ antigen solution at concentrations ranging from 0.08 to $10 \mu \mathrm{g}$ were added to the plasticized discs in flat-bottomed microplates and left to stand overnight at $25^{\circ} \mathrm{C}$ for $1 \mathrm{~h}$, for 
protein (F1 antigen) immobilization.

Blocking conditions. The conditions used were as described by Araujo et al. (13).

Conjugate tritation. Goat anti-rabbit IgG conjugated with horseradish peroxidase was diluted from 1:1,500 to 1:24,000 in PBS.

Serum titration. Positive sera were diluted from 1:400 to $1: 51,200$ in PBS and ELISA was carried out using the best conditions for blocking, conjugate dilution and antigen concentration.

\section{Results and Discussion}

Several polymers have been investigated as an alternative solid phase to be used in immunoassays. Lehtonen and Viljanen (16), studying the concentration of antigen in ELISA for the detection of chicken antibovine serum albumin, used three polymers as solid phase and two immobilization procedures: polystyrene and nylon (adsorption) and cyanogen bromide-activated paper (covalent link). There was a noticeable release of the adsorbed antigen during the assay from both polystyrene (30\%) and nylon $(60 \%)$. Desorption of antigen from activated paper during the assay was lower than with polystyrene or nylon. Bode et al. (17), studying the detection of antigen of four adenoviruses and anti-adenoviruses, reported the sensitivity of the membrane discs (nitrocellulose) to be 9-10-fold higher than in a conventional ELISA using polystyrene solid phase supports.

De Saeger and Van Peteghem (18) proposed a dipstick enzyme immunoassay for rapid antigen detection on a membrane precoated with rabbit anti-mouse immunoglobulins and monoclonal anti-T-2 toxin antibodies for the detection of Fusarium T-2 toxin in wheat.

In the present study, ELISA was based on the covalent link of F1 antigen on discs of filter paper plasticized with polyvinyl alcohol-glutaraldehyde.

Figure 1 shows the relationship between the concentration of F1 antigen on the proposed matrix and the results obtained by ELISA. A typical hyperbolic MichaelisMenten curve (19) obtained due to the saturation of antigen-antibody complex revealed that the minimum amount of fixed antigen to produce maximum absorbance is equal to $1.25 \mu \mathrm{g}$ protein. Figure 2 shows the relationship between goat anti-rabbit IgG conjugate dilution and ELISA performance. The 1:12,000 dilution can be used as the best conjugate concentration. The titration of immunized and non-immunized serum against F1 antigen, illustrated in Figure 3, shows that a 1:6,200 dilution would be recommended since the highest $\mathrm{F}$ factor value was estimated at this concentration $(F \cong 12)$. A remarkable difference in absorbance was observed between immunized and non-immunized sera, while values close to zero were detected for the control (PBS).
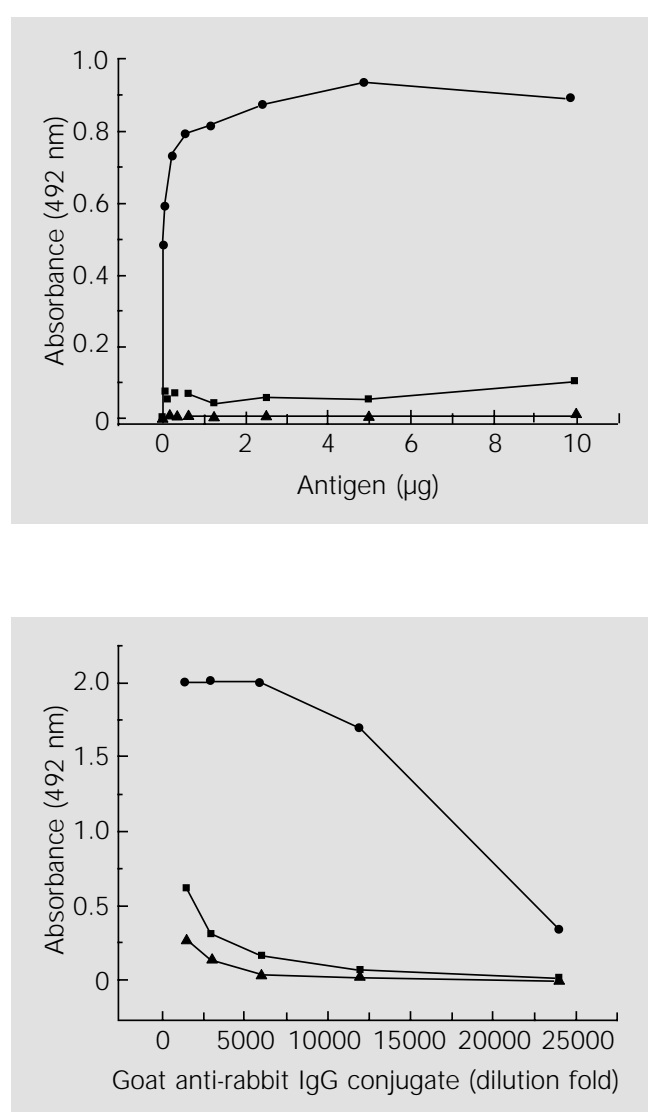

Figure 1 - Relationship between antigen immobilized (F1) on discs of filter paper plasticized with polyvinyl alcohol-glutaraldehyde and ELISA results. DiscS containing F1 antigen (100 $\mu$ l) with protein concentrations ranging from 0.08 to $10 \mu \mathrm{g}$ were incubated with $100 \mu \mathrm{l}$ of immunized serum diluted 1:6,400 (circles), non-immunized serum (squares) and PBS (triangles). Goat anti-rabbit IgG conjugate $(100 \mu l)$ diluted 12,000 times and substrate solution $(100 \mu \mathrm{l})$, including OPD and $\mathrm{H}_{2} \mathrm{O}_{2}$, were used. The discs were removed and the absorbance of the supematant at $492 \mathrm{~nm}$ was determined with an ELISA reader.

Figure 2 - Titration of goat antirabbit IgG conjugated with horseradish peroxidase by ELISA using paper filter plasticized with polyvinyl alcohol-glutaraldehyde as solid phase. The conjugate was diluted from $1: 1,500$ to $1: 24,000$ in PBS and ELISA was carried out using $1.25 \mu \mathrm{g}$ antigen/disc and $100 \mu \mathrm{l}$ of immunized serum diluted 1:6,400 (circles), non-immunized serum (squares) and PBS (triangles). 
The antigen/plasticized discs used for this serum titration were impregnated by the colored products released during ELISA development (OPD oxidation by peroxidase). The color intensity was directly proportional to absorbance and remained unaltered for about two days. Thus, one can set up a dot-ELISA based on this antigen/plasticized discs.

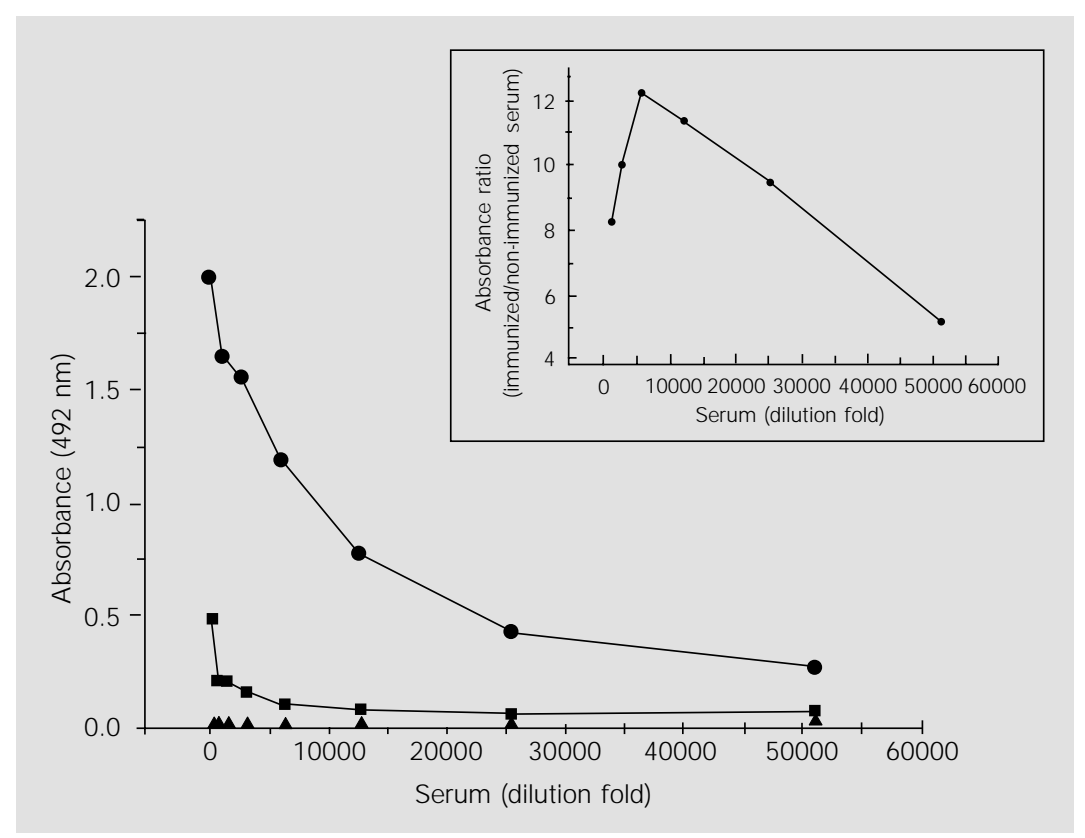

Figure 3 - Titration of serum from rabbits immunized or not against F1 antigen by ELISA using filter paper plasticized with polyvinyl alcohol-glutaraldehyde. Sera $(100 \mu l)$ from immunized rabbit (circles), non-immunized rabbit (squares) and PBS (triangles) were diluted from 1:400 to 1:51,200 in PBS and ELISA was carried out according to the best conditions for antigen (1.25 $\mu \mathrm{g} / \mathrm{disc}$ ) and conjugate concentration (diluted 1:12,000). Insert, The ratio (factor F) between the absorbance values recorded for the immunized and non-immunized serum was calculated for each dilution.

Figure 4 - Comparison of the absorbance values obtained by conventional ELISA based on polyvinyl chloride (PVC) and ELISA based on filter paper plasticized with polyvinyl alcohol-glutaraldehyde. Sera from immunized $(\mathrm{N}=8)$ and non-immunized $(\mathrm{N}=9)$ rabbits were analyzed for the presence of anti-F1 antigen IgG. The absorbance reported is the mean of two determinations. The arrows indicate the positions of the mean values.

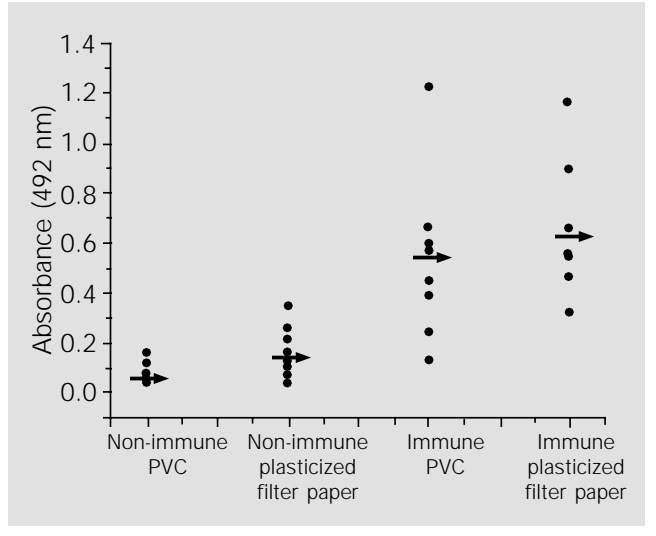

A comparative study between this method and conventional ELISA based on antigen adsorption on polyvinyl chloride plates is shown in Figure 4. In this experiment, sera were collected from immunized rabbits $(\mathrm{N}=$ 8 ) and non-immunized rabbits ( $N=9)$. Firstly, regarding the sera from immunized rabbits, the mean values $( \pm \mathrm{SD})$ of $0.667 \pm 0.264$ and $0.536 \pm 0.326$ were calculated for the ELISA absorbance values using plasticized filter paper and conventional procedures, respectively. The independent $t$-test applied to both mean values at the 0.05 level showed no significant difference $(\mathrm{t}=0.875$ and $\mathrm{P}=$ 0.396). Also, a linear correlation was observed when plasticized filter paper values were plotted against those obtained by the conventional procedure $(\mathrm{r}=0.986$ and $\mathrm{P}=$ $0.00037)$. For the sera collected from nonimmunized rabbits $(\mathrm{N}=9)$ mean values of $0.127 \pm 0.103$ and $0.065 \pm 0.045$ were estimated for the plasticized filter paper and conventional ELISA procedures, respectively. The independent $t$-test between these values was not significant $(\mathrm{t}=1.652$ and $\mathrm{P}=$ 0.118 ). A linear correlation was also observed between the two procedures $(\mathrm{r}=0.952$ and $\mathrm{P}=0.00007$ ). In summary, ELISA performed on this basis is comparable to that performed by the conventional procedure.

The present results indicate that filter paper plasticized with polyvinyl alcohol-glutaraldehyde can be an alternative support for immunoassays. It is easy to synthesize and the antigen is covalently linked, therefore avoiding false-negative results due to antigen leaching. The reagents are of low cost and easy acquisition; ELISA and dot-ELISA can be simultaneously performed either in the laboratory or in the field. Small amounts of antigen $(1.25 \mu \mathrm{g})$ and conjugate (dilution $1: 12,000)$ were employed in the present model (experimental plague). High sensitivity was also achieved (serum dilution up to 1:51,200 still revealed differences between immunized and non-immunized serum, with an $\mathrm{F}$ factor higher than 5). 


\section{References}

1. Butler T (1989). The Black Death past and present. 1. Plague in the 1980s. Transactions of the Royal Society of Tropical Medicine and Hygiene, 83: 458-460.

2. Chanteau S, Ratsifasoamanana L, Rasoamanana B, Rahalison L, Randriambelosoa J, Roux J \& Rabeson D (1998). Plague, a reemerging disease in Madagascar. Emerging Infectious Diseases, 4: 101-104

3. Vieira J BF, Almeida AMP \& Almeida CR (1994). Epidemiologia e controle da peste no Brasil. Revista da Sociedade Brasileira de Medicina Tropical, 27 (Suppl III): 51-58.

4. Perry RD \& Fetherston J D (1997). Yersinia pestis - etiologic agent of plague. Clinical Microbiology Reviews, 10: 35-66.

5. Almeida AM, Leal NC, de Carvalho FG, Dantas Sobrinho J \& de Almeida CR (1995). Plague surveillance in Brazil: 19831992. Revista do Instituto de Medicina Tropical de São Paulo, 37: 511-516.

6. Almeida AM \& Ferreira LC (1992). Evaluation of three serological tests for the detection of human plague in northeast Brazil. Memórias do Instituto Oswaldo Cruz, 87: 87-92.

7. Leroy $F$ (1997). Etude séro(-)épidémiologique de la peste humaine à Madagascar. Annales de Biologie Clinique, 55: 332336.

8. Cao LK, Anderson GP, Ligler FS \& Ezzell J
(1995). Detection of Yersinia pestis fraction 1 antigen with a fiber optic biosensor. J ournal of Clinical Microbiology, 33: 336341.

9. Anderson GP, King KD, Cao LK, J acoby M, Ligler FS \& Ezzell J (1998). Quantifying serum antiplague antibody with a fiberoptic biosensor. Clinical and Diagnostic Laboratory Immunology, 5: 609-612.

10. Leal NC, Abath FG, Alves LC \& de Almeida AM (1996). A simple PCR-based procedure for plague diagnosis. Revista do Instituto de Medicina Tropical de São Paulo, 38: 371-373.

11. Montenegro SML, De Almeida AMP, Carvalho AB \& Carvalho J r LB (1991). The use of Dacron plates for dot enzymelinked immunosorbent assay (dot-ELISA). Memórias do Instituto Oswaldo Cruz, 86: 461-465.

12. Montenegro SML, Almeida AMP \& Carvalho J r LB (1993). Standardization of the dot enzyme-linked immunosorbent assay (dot-ELISA) for experimental plague. Memórias do Instituto Oswaldo Cruz, 88: 119-123.

13. Araujo AM, Petribú ATS, Barbosa GHTS, Diniz J RP, Almeida AMP, Azevedo WM, Malagueño E \& Carvalho J r LB (1996). The use of polyvinyl alcohol glutaraldehyde as solid-phase in ELISA for plague. Memórias do Instituto Oswaldo Cruz, 91:
195-198.

14. Carvalho J r LB, Araujo AM, Almeida AMP $\&$ Azevedo WM (1996). The use of polyvinyl alcohol glutaraldehyde antigen coated discs for laser induced fluorescence detection of plague. Sensors and Actuators, B 35-36: 1-4.

15. Baker EE, Sommer H, Foster LE, Meyer E $\&$ Meyer KF (1952). Studies on immunization against plague. I. The isolation and characterization of the soluble antigen of Pasteurella pestis. Journal of Immunology, 68: 131-140.

16. Lehtonen OP \& Viljanen MKJ (1980). Antigen attachment in ELISA. J oumal of Immunological Methods, 34: 61-70.

17. Bode L, Beutin L \& Köhler HJ (1984). Nitrocellulose-enzyme-linked immunosorbent assay (NC-ELISA) - a sensitive technique for the rapid visual detection of both viral antigens and antibodies. J ournal of Virological Methods, 8: 111-121.

18. De Saeger S \& Van Peteghem C (1996). Dipstick enzyme immunoassay to detect Fusarium T-2 toxin in wheat. Applied and Environmental Microbiology, 62: 18801884.

19. Van-Heyningen $V$, Brock DJ \& vanHeyningen S (1983). A simple method for ranking the affinities of monoclonal antibodies. J ournal of Immunological Methods, 62: 147-153. 